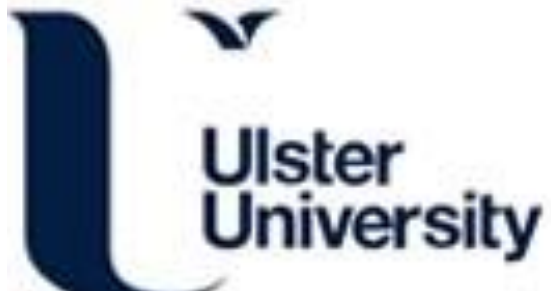

The influence of the user in body centric antennas and propagation at $3-6 \mathrm{GHz}-\mathrm{a}$ Rician K-factor approach

Catherwood, P., \& Scanlon, W. (2014). The influence of the user in body centric antennas and propagation at 3-6 GHz-a Rician K-factor approach. IEEE Antennas and Wireless Propagation Letters, 13, 907-910. https://doi.org/10.1109/LAWP.2014.2316248

Link to publication record in Ulster University Research Portal

\section{Published in:}

IEEE Antennas and Wireless Propagation Letters

Publication Status:

Published (in print/issue): 01/01/2014

DOI:

10.1109/LAWP.2014.2316248

\section{Document Version}

Publisher's PDF, also known as Version of record

\section{General rights}

Copyright for the publications made accessible via Ulster University's Research Portal is retained by the author(s) and / or other copyright owners and it is a condition of accessing these publications that users recognise and abide by the legal requirements associated with these rights.

\section{Take down policy}

The Research Portal is Ulster University's institutional repository that provides access to Ulster's research outputs. Every effort has been made to ensure that content in the Research Portal does not infringe any person's rights, or applicable UK laws. If you discover content in the Research Portal that you believe breaches copyright or violates any law, please contact pure-support@ulster.ac.uk. 


\title{
The Influence of the User in Body-Centric Antennas and Propagation at 3-6 GHz-A Rician $K$-Factor Approach
}

\author{
Philip A. Catherwood and William G. Scanlon, Senior Member, IEEE
}

\begin{abstract}
We investigate whether the presence of a human body in wearable communications should be considered as part of the radiating structure or as part of the local radio environment. The Rician $K$-factor was employed as a quantitative measure of the effect of the user's body for five environments and two mounting locations. Presented empirical results indicated that the environment had a greater impact on the $K$-factor values than the position of the transmit antenna for the ultrawideband signals used, confirming that the human body should be considered primarily as part of the overall radiating system when the antenna is worn on the body. Furthermore, independent variations also existed in the $K$-factor values for the differing antenna-body mounting positions, indicating that as the position changed, then the radiating effects and the contribution from the body changed. This is significant for ensuring body-antenna systems are accurately modeled in system-level simulations.
\end{abstract}

Index Terms-Body-centric, environment, radiating structure, Rician $\boldsymbol{K}$-factor, ultrawideband (UWB).

\section{INTRODUCTION}

I N RECENT times, body-centric communications have enjoyed a considerable amount of interest [1]. It has long been recognized that for wearable antennas, the human body is a critical part of the RF channel [2]. In the transmission of UHF/SHF radio signals, the human body can have various effects on the radiated electromagnetic waves, including shadowing, scattering, and reflection. Depending on the local conditions and positioning relative to the transmit and/or the receive antenna, the human body has been considered a part of the radio transmission medium [3], as part of the temporal environment for mobile pedestrians [4], and as having a directionality effect on off-body communication links [5].

In recent years, [6] presented electric field modeling of bodycentric antennas at UHF frequencies that highlighted the human body is an integral part of the radiating structure. Reference [7] believes that human bodies within the radio channel are part of the environment because their presence causes variations in the indoor radio channel environment. They categorize human bodies as being a temporal part of the radio channel, while

Manuscript received March 03, 2014; accepted March 17, 2014. Date of publication April 11, 2014; date of current version May 15, 2014.

The authors are with the ECIT, Queen's University Belfast, Belfast BT3 9DT,

U.K. (e-mail: p.catherwood@qub.ac.uk; w.scanlon@qub.ac.uk).

Color versions of one or more of the figures in this letter are available online at $\mathrm{http}: / /$ ieeexplore.ieee.org.

Digital Object Identifier 10.1109/LAWP.2014.2316248 building structures and fixings are classified as the spatial part. This supported previous work by [3], who viewed pedestrians as moving obstacles in the environment, with partitions, walls, etc., being stationary obstacles. While a number of these papers have addressed facets of the hypothesis, to date no published work has definitively determined an answer, thus contributing to varying (and therefore not necessarily comparable) model parameters for computer simulations.

This letter utilizes the Rician $K$-factor to investigate if the human body, to which the antennas have been mounted in off-body networks, should be considered part of the radiating antenna structure or part of the surrounding multipath environment.

\section{Theoretical Principles}

While the Rician $K$-factor is a descriptive parameter of the reflectivity of a given environment, it is also a quantitative measure of the same. It is generally accepted that the value of $K$ will be high for low multipath environments and low for high multipath environments - the $K$-factor being the ratio of power in the dominating multipath component to power in the other multipath components.

Recent literature provides examples of the use of Rician $K$-factor as a metric of the environment, showing it can be used to characterize fading from multiple human pedestrians [8], provide an indication of channel status [9], determine optimal Rayleigh stirring conditions for reverberation chambers [10], and specify a radio channel's frequency-selective nature [11].

\section{Environment, EQuiPMent, AND PRocedure}

A series of rotation measurements was recorded in two environments: an anechoic chamber and a hospital ward. The anechoic chamber was a $10 \times 5.4-\mathrm{m}^{2}$ structure located on the ground floor of the ECIT building at Queen's University, Belfast, U.K., housed in conductive shielding and lined with pyramidal RF absorbers [12]. The multipath environment was a $7.5 \times 7.5-\mathrm{m}^{2}$ specialist nurse training room at the University of Ulster, U.K. [13], that faithfully recreates a real hospital ward and is fitted with regulation beds, rails, bedside cabinets, etc. [Fig. 1(a)]. The building was of 1960s construction, consisting mainly of double concrete-block cavity external walls, single-brick internal walls, and concrete floor. A suspended ceiling supports luminaries at $2.8 \mathrm{~m}$ above floor level.

The optic-fiber-based body-worn ultrawideband (UWB) channel characterization system was previously used in [12] 


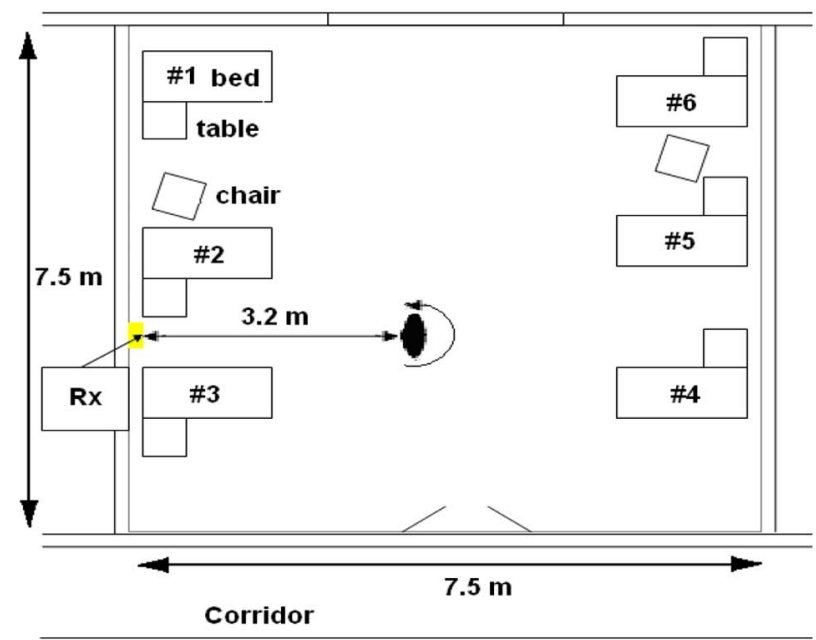

(a)

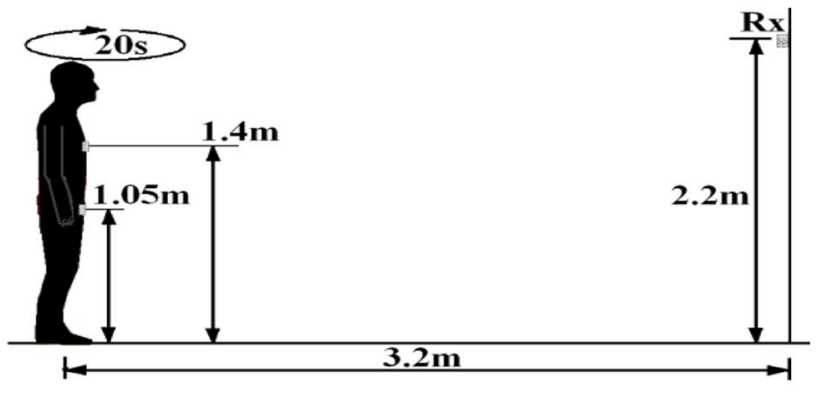

(b)

Fig. 1. (a) Hospital ward floorplan. (b) Rotation measurement configuration.

and [13] and consisted of a vertically polarized perpendicular low-profile SMD body-mounted UWB transmit chip antenna (Fractus UM-FR05-S1-P-0-107) connected to a battery-powered FCC-compliant PulsON 210 UWB source from TimeDomain, with a center frequency of $4.7 \mathrm{GHz}$, bandwidth of $3.2 \mathrm{GHz}$, and launch power of $-12 \mathrm{dBm}$. The body-mounted antenna was fed via a $1.5-\mathrm{m}$ RF-over-fiber link (9/125 single mode at $1550 \mathrm{~nm}, 0 \mathrm{~dB}$ gain). This consisted of an optical transmitter (SCML-50K6G by Miteq) connected to the UWB source, both of which were held in a waist holster, and an optical receiver (MiniPR by Linphotonics) was connected to the chest or waist-mounted transmit antenna assembly.

The transmitted off-body signals were received by a stationary PulsON UWB receiver system using a vertically polarized perpendicular PulsON UWB antenna. A laptop recorded real-time channel impulse response (CIR) data scans at 100 scans per second. Each scan was post-processed to remove effects of the transceiver system components by deconvolving the received CIR from a reference measurement (with an isolated antenna) using a frequency domain technique to leave only the impulse response transfer function of the propagation channel, and furthermore transformed into the form of a power delay profile (PDP). The reference measurement was recorded for a freestanding direct line-of-sight (LOS) link at an antenna separation of $3.2 \mathrm{~m}$ in an anechoic chamber with the transmit and receive antennas face to face. The antenna bandwidth measured on the body was previously reported in [14].

Rotation tests were completed in the two environments for the UWB antenna measurement system. Initially, the user (and hence

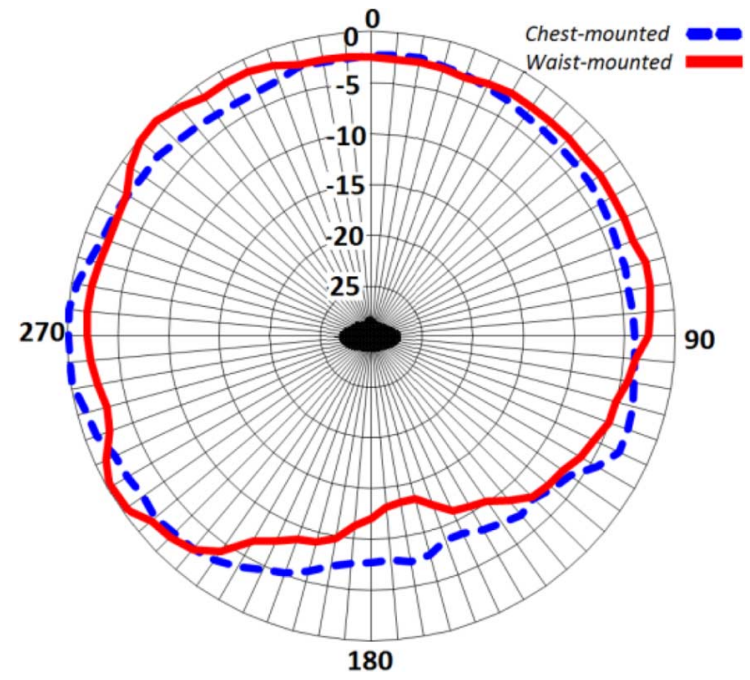

Fig. 2. Wideband azimuthal radiation patterns measured in anechoic chamber.

the transmit antenna) was directly facing the receiver module $\left(0^{\circ}\right)$, and a rotation lasting $20 \mathrm{~s}$ (constant angular speed of $18^{\circ} / \mathrm{s}$ ) was undertaken. These tests were completed for the transmit antenna mounted on the chest (at a height of $1.4 \mathrm{~m}$ ) and on the waist (at a height of $1.05 \mathrm{~m}$ ). In the anechoic chamber, the receive antenna was mounted on a freestanding platform at a height of $2.2 \mathrm{~m}$ above the ground [Fig. 1(b)]; in the hospital ward, the receive antenna was placed between beds $\# 2$ and $\# 3$ at a height of $2.2 \mathrm{~m}$ to represent a base-station access point [Fig. 1(b)].

For all tests, the antenna was held against the body using an adjustable synthetic elastic band to minimize body-antenna separation during testing (antenna-skin separation of $20 \mathrm{~mm}$ ) [12], [13]. For waist tests, all metallic items such as belts and coins were removed from the user to ensure no distortion of results occurred. The test subject selected for the experiments was an adult male of mass $82 \mathrm{~kg}$ and height $1.78 \mathrm{~m}$. For each of these simple rotation tests, the PDPs were recorded at a rate of 100 samples per second $\left(0.18^{\circ} /\right.$ sample). For each scenario, 2000 power delay profiles were recorded and processed to calculate the range of Rician $K$-factors. The power in the direct ray component was calculated using the first detectable pulse in the PDP (position and duration checked manually for every scan); the power in the multipath components was considered to be every received signal above the noise threshold following the first detectable pulse in the PDP. The length of each scan was $130 \mathrm{~ns}$; as experimentation confirmed, this exceeded the limit for all observable signal components.

\section{RESUlTS AND DISCUSSION}

Fig. 2 presents a wideband azimuthal radiation pattern for a chest-mounted and a waist-mounted antenna measured in the anechoic chamber. Received power for both has been normalized to the highest received power, which was for the chest antenna at $-64.1 \mathrm{dBm}$. The range of received power values was $8.6 \mathrm{~dB}$ for the chest and $13.4 \mathrm{~dB}$ for the waist. This illustrates how placing a UWB antenna on two differing parts of the human body yields different radiation patterns due to the differing body compositions [15]. 

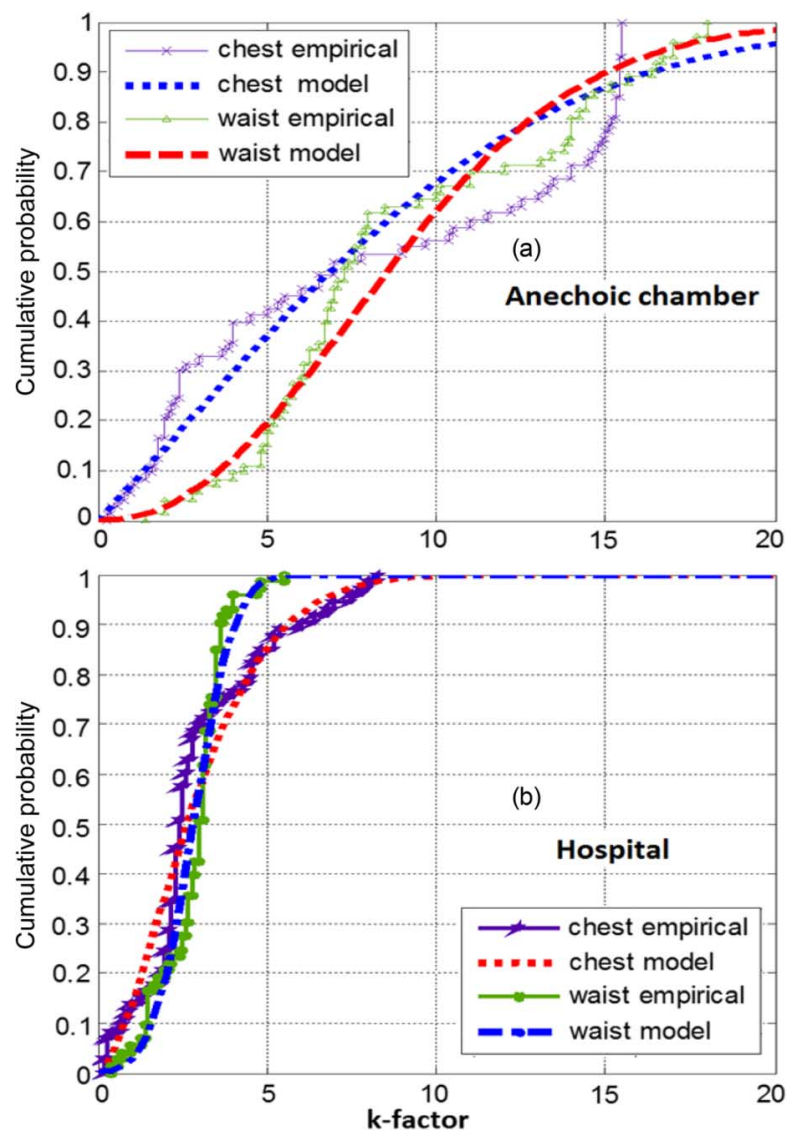

Fig. 3. Cumulative distribution functions of Rician $K$-factor values for various rotation measurements. (a) Anechoic chamber. (b) Hospital.

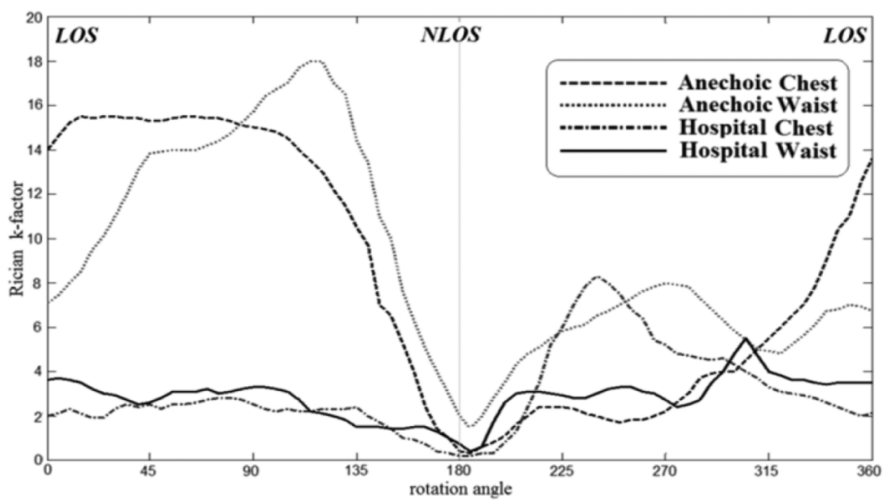

Fig. 4. Rician $K$-factor values versus rotation angle.

A graphical representation of the collated results in the form of cumulative distribution functions (CDFs) is presented for $K$-factor values for the two antenna height positions on the body (chest and waist) and for both environments in Fig. 3. Fig. 4 displays how the Rician $K$-factor changes in each scenario as the angle of alignment with the receiver changes.

The results show that, in the anechoic chamber, the waist had a marginally higher mean $K$-factor value (9.0) over the full rotation compared to the chest (8.2). In the hospital environment, the opposite was true: this time, 3.0 for the chest versus 2.8 for the waist. It was evident that the $K$-factor values for both the various body-antenna mounting points in the anechoic chamber were much higher than those found in the hospital environment. This illustrates that the local environment has a much greater
TABLE I

STATISTICAL PARAMETERS FOR RiCIAN $K$-FACTOR CDFs

\begin{tabular}{ccccccc}
\cline { 2 - 7 } & Position & Distribution & Est. & Std.Err. & Est. & Std.Err. \\
\hline \multirow{3}{*}{ Anechoic } & Chest & Nakagami & $\mu=0.53$ & $\mu=0.07$ & $\Omega=100$ & $\Omega=16$ \\
\cline { 2 - 7 } & Waist & Nakagami & $\mu=1.12$ & $\mu=0.16$ & $\Omega=101$ & $\Omega=11$ \\
\hline \multirow{3}{*}{ Hospital } & Chest & Weibull & $\mathrm{a}=3.33$ & $\mathrm{a}=0.26$ & $\mathrm{~b}=1.60$ & $\mathrm{~b}=0.14$ \\
\cline { 2 - 7 } & Waist & Normal & $\mu=2.83$ & $\mu=0.11$ & $\Sigma=0.96$ & $\Sigma=0.08$ \\
\hline
\end{tabular}

effect on the $K$-factor than antenna-body positioning. Over the full rotation, the chest and waist $K$-factor values were found to be generally similar in the hospital environment except for a notable difference between $210-300^{\circ}$, where the chest $K$-factor was much greater than the waist $K$-factor. This is due to the effects of a thick metal-framed window positioned at chest height reflecting RF power toward the receive antenna. This is in comparison to the walls that were covered with scatterers (lamps, monitors, cabinets) and thus reflected less than the smooth metal frame.

In the anechoic chamber, the chest-mounted antenna had a smaller range of $K$-factor values (15.2) than the waist-mounted antenna (16.6). In the hospital environment, however, the converse was true: 8.1 for the chest versus 5.1 for the waist. In comparing the range of $K$ values with respect to the environments, it is evident the differences between the chest and waist are minor when compared to the considerably more prominent differences in $K$-value range for the anechoic chamber and hospital, with the spread of values in the anechoic chamber being much larger than the range for the hospital environment (Fig. 3). Additionally, the CDF for the anechoic chamber displays bimodal properties, whereas the hospital only exhibits unimodal characteristics, again highlighting the environment's greater effect on the $K$-factor.

To mathematically describe the range of Rician $K$-factor parameters, the maximum likelihood (ML) estimates of Rician $K$-factor for each scenario were calculated for common statistical distributions, and the Akaike information criterion (AIC) [16] was used to select the closest fitting distribution.

In the anechoic chamber, both chest and waist are best described by the Nakagami distribution, although each have differing statistical parameters (Table I), reflecting the differing radiation patterns (Fig. 2). While Nakagami is typically used when modeling fading in communication channels, there is a growing body of work that uses it to describe other numerical series; reference [17] is one such example. It is thus presented here as the most appropriate model by which to mathematically describe the distribution of the recorded Rician $K$-factor values in the anechoic chamber.

In the hospital environment, the chest and waist $K$-factor CDFs are described by different statistical distribution models (Weibull for the chest; Normal for the waist). These two distributions are considered quite similar for sizable data sets [18], suggesting the mathematical description for both the chest and waist values are also similar. It is also noted that differing antenna positions have relatively small influence on the mean, spread, and CDF profile of the K-factor values, whereas the differing environment has a comparably large impact. Overall, the 
TABLE II

RICIAN $K$-FACTOR FOR FIVE ENVIRONMENTS

\begin{tabular}{ccccccc} 
& & Anechoic & Hospital & Office & Corridor & Reverb. \\
\cline { 3 - 7 } LOS & Chest & 15.1 & 3.3 & 1.7 & 1 & 0.45 \\
\cline { 2 - 7 } & Waist & 18.2 & 4.1 & 2.2 & 1.3 & 0.35 \\
\hline \multirow{2}{*}{ NLOS } & Chest & 0.5 & 0.3 & 0.26 & 0.21 & 0.12 \\
\cline { 2 - 7 } & Waist & 0.65 & 0.4 & 0.33 & 0.27 & 0.15 \\
\hline
\end{tabular}

environment had substantively more of a consequence on the $K$-factor values than the position of the transmitting antenna, inferring that the human body should be considered primarily as part of the overall radiating system when the antenna is worn upon the body.

\section{VALIDATION IN ADDITIONAL ENVIRONMENTS}

To validate the above conclusions, additional measurements were recorded in five different environments (including the two formerly presented), each offering different physical layouts and multipath characteristics (Table II). The additional three environments were a $40-\mathrm{m}^{2}$ modern computer classroom located in Northern Regional College, U.K.; a 260- $\mathrm{m}^{2}$ corridor situated on the fifth floor of Block 1 of the University of Ulster; and a $5.8-\mathrm{m}^{2}$ reverberation chamber on the ground floor of ECIT (Queen's University, Belfast). Measurements were either direct $\operatorname{LOS}$ or $180^{\circ}$ rotated [non-line-of-sight (NLOS)] and performed for both chest- (height of $1.4 \mathrm{~m}$ ) and waist-mounted antennas $(1.05 \mathrm{~m})$, with the receive antenna wall mounted at $2.2 \mathrm{~m}$ in each environment.

The percentage difference of the $K$-factor values between the chest and the waist in each of the five environments for both LOS and NLOS trial arrangements yields comparable values (percentage difference of $K$-factor for LOS was 23.4 with standard deviation (SD) of 3.2, and for NLOS 25.1 with SD of 2.4), indicating that relative $K$-factor values due to the chest and waist mounting are not significantly affected as the environment changes from very low to very high reflectivity. However, the percentage difference between the minimal environment (anechoic chamber) and the four multipath environments reveals that as reflectivity increases, so too do the percentage differences of $K$-factor for those environments. As the percentage difference between the chest and the waist presents similar values for each of the five environments yet percentage difference between the minimal environment and the four multipath environments display an increasing trend with environmental reflectivity, these tests add further compelling evidence that the human body should be considered part of the radiating structure and not its surrounding environment.

\section{CONCLUSION}

Empirical results for the Rician K-factor experiments show the environmental parameters were considerably more significant on $K$-factor values than the location of the transmitter antenna upon the human body, implying that the human body is primarily an integral part of the radiating structure in this frequency band. This outcome is significant as it lays the foundation for how the presence of a human body should be classified in empirical measurement campaigns and computer models. The conclusions of this work are also valid for radio frequencies lower than those presented here, as the geometry between the antenna structure and the human body will typically ensure the body continues to be in the near-field region. It is considered that the results are also generally applicable for higher frequency systems. However, at greatly higher frequencies, the majority of the body on which the antenna is attached will move into the far-field region. Further research would include work to understand how moving limbs and directional antennas would affect the $K$-factor values.

\section{REFERENCES}

[1] I. Khan and P. S. Hall, "Multiple antenna reception at 5.8 and $10 \mathrm{GHz}$ for body-centric wireless communication channels," IEEE Trans. Antennas Propag., vol. 57, no. 1, pp. 248-255, Jan. 2009.

[2] T. B. Welch et al., "The effects of the human body on UWB signal propagation in an indoor environment," IEEE J. Sel. Areas Commun., vol. 20, no. 9, pp. 1778-1782, Dec. 2002.

[3] Q. Wang and J. Wang, "Performance of on-body chest-to-waist UWB communication link," IEEE Microw. Wireless Compon. Lett., vol. 19, no. 2, pp. 119-121, Feb. 2009.

[4] M. Klepal, R. Mathur, A. McGibney, and D. Pesch, "Influence of people shadowing on optimal deployment of WLAN access points," in Proc. IEEE Veh. Technol. Conf., 2004, pp. 4516-4520.

[5] S. Hara, D. Anzai, K. Yanagihara, K. Takizawa, and K. Hamaguchi, "A cooperative transmission scheme for real-time data gathering in a wireless body area network," in Proc. 22nd IEEE PIMRC, Sep. 11-14, 2011, pp. 2254-2258.

[6] K. Ito and N. Haga, "Wearable antennas for body-centric wireless communications," in Proc. Int. Conf. Appl. Electromagn. Student Innov. Competition Awards, Aug. 11-13, 2010, pp. 129-133.

[7] A. Jraifi, E. H. Saidi, A. El Khafaji, and J. El Abbadi, "A temporal variation in indoor environment," Proc. Eur. Comput. Conf., vol. 27, no. 6, pp. 523-532, 2009.

[8] P. K. Chong, S. Yoo, S. Kim, and D. Kim, "Wind-blown foliage and human-induced fading in ground-surface narrowband communications at $400 \mathrm{MHz}$," IEEE Trans. Veh. Technol., vol. 60, no. 4, pp. 1326-1336, May 2011.

[9] C. Tepedelenlioglu, A. Abdi, and G. B. Giannakis, "The Ricean K factor: Estimation and performance analysis," IEEE Trans. Wireless Commun., vol. 2, no. 4, pp. 799-810, Jul. 2003.

[10] C. Lemoine, E. Amador, and P. Besnier, "Mode-stirring efficiency of reverberation chambers based on Rician K-factor," Electron. Lett., vol. 47, no. 20, pp. 1114-1115, Sep. 2011.

[11] R. Prasad, "OFDM for wireless communications systems," in Artech House Universal Personal Communications Series. Boston, MA, USA: Artech House, 2004.

[12] P. A. Catherwood and W. G. Scanlon, "Measurement errors introduced by the use of co-axial cabling in the assessment of wearable antenna performance in off-body channels," in Proc. EuCAP, Rome, Italy, Apr. 11-15, 2011, pp. 3787-3791.

[13] P. A. Catherwood and W. G. Scanlon, "Off-body UWB channel characterisation within a hospital ward environment," Int. J. Ultra Wideband Commun. Syst., vol. 1, no. 4, pp. 263-272, 2010.

[14] L. Xia, S. Redfield, and P. Chiang, "Experimental characterization of a UWB channel for body area networks," EURASIP J. Wireless Commun. Netw., vol. 2011, p. 703239, 2011.

[15] N. Chahat, M. Zhadobov, R. Sauleau, and K. Mahdjoubi, "Parametric analysis of on-body dual-band antenna performance: Dependence on the human body morphology," in Proc. EuCAP, Rome, Italy, Apr. 11-15, 2011, pp. 437-440.

[16] C. U. Bas and S. C. Ergen, "Ultra-wideband channel model for intravehicular wireless sensor networks beneath the chassis: From statistical model to simulations," IEEE Trans. Veh. Technol., vol. 62, no. 1, pp. 14-25, Jan. 2013.

[17] X. Yang, P. Rossi, D. Bruner, S. Tridandapani, J. Shelton, and T. Liu, "Noninvasive evaluation of vaginal fibrosis following radiotherapy for gynecologic malignancies: A feasibility study with ultrasound B-mode and Nakagami parameter imaging," Med. Phys., vol. 40, no. 2, pp. 022901.1-022901.7, 2013.

[18] H. V. Kulkarni and S. K. Powar, "A simple normal approximation for Weibull distribution with application to estimation of upper prediction limit," J. Probab. Statist., vol. 2011, p. 863274, 2011. 